\title{
Activity patterns of primary auditory-nerve fibres in chickens: Development of fundamental properties
}

\author{
Geoffrey A. Manley, Alexander Kaiser, Jutta Brix and Otto Gleich \\ Institut für Zoologie der Technischen Universität München, Garching, F.R.G.
}

(Received 11 February 1991; accepted 10 July 1991)

\begin{abstract}
We have examined the activity patterns of single auditory-nerve fibres in the chicken and tested for possible changes during post-hatching development. For this purpose, we recorded from fibres in the cochlear ganglion of chickens of two age groups (about P2 and P21) and investigated their spontaneous and sound-evoked activity patterns under nembutal-chloralhydrate anaesthesia. The spontaneous activity of primary auditory neurones was irregular, the average rates were between 20.5 (P2) and 23 (P21) spikes/s. Many low-frequency fibres from both age groups showed preferred intervals in their spontaneous activity. Tuning characteristics, including the range of characteristic frequencies, the presence of primary and two-tone suppression, the slopes of tuning-curve flanks and $Q_{10 \mathrm{~dB}}$ values were similar to those previously reported for the starling and were statistically indistinguishable between the two age groups. However, there was a difference in fibre thresholds at the highest frequencies. Systematic differences were also present between the two age groups with regard to some characteristics of the rate-intensity functions. These data indicate that whereas the tuning propcrtics of primary auditory fibres of the chicken cochlea are mature as early as post-hatching day 2 , the intensity functions are not.
\end{abstract}

Development; Chicken; Primary auditory neurones; Cochlear ganglion; Auditory physiology; Bird

\section{Introduction}

During the last ten years, there has been a rapid growth of interest in the ontogeny of hearing. Most studies of the development of the avian cochlea have been carried out in precocious species, such as chickens and ducks. The cochlea of the domestic chicken is almost fully developed at hatching. While the actual length of the sensory epithelium does increase after hatching (Ryals et al., 1984; Manley et al., 1987), most features of the fine anatomy have reached their adult appearance by the time of hatching. These features include the differentiation of the tectorial membrane (Cohen and Fermin, 1985) and of the hair-cell stereovillar bundles (Cotanche and Sulik, 1984; Tilney et al., 1986), the maturation of the tall and short hair cells and the hair-cell innervation (Fermin and Cohen, 1984a; Rebillard and Pujol, 1983; Whitehead and Morest, 1985a,b). Some other features, such as the myelination of the statoacoustic ganglion (Fermin and Cohen, 1984b) are only fully developed a week or two after hatching. Similarly in the duck, cell differentiation and synaptogenesis are essentially complete at hatching (Chandler, 1984). Anatomical and physiological devel-

Correspondence to: G.A. Manley, Institut für Zoologie, Technische Universität München, Lichtenbergstrasse 4, W-8046 Garching, F.R.G. opment in the hearing organ do not, however, take place in a completely parallel fashion.

A number of studies indicate that morphologically, the basal-to-middle region of the basilar papilla matures before the apical region. The hair cells on the basilar papilla mature first at the basal end, the place where high frequencies are analyzed (Fermin and Cohen, 1984a; Hirokawa, 1978). In contrast, the results of a number of behavioural (Gray and Rubel, 1985) and physiological experiments recording from brain-stem nuclei (Lippe, 1987; Lippe and Rubel, 1985) suggest that hatched chickens have a delayed maturation of high-frequency hearing. It has thus been assumed that, in contrast to structural maturation, functional maturation begins first in the apex and shifts with time to the base. Rubel and Ryals (1983) suggested that there is a maturation of peripheral function until at least day P30. This phenomenon of contrary maturational gradients has been described as a paradox (Rubel and Ryals, 1983).

On the other hand, some other published reports have indicated essentially adult responses in the cochlea of the newly-hatched chicken. Saunders et al. (1973), for example, found little shift of the best frequency sensitivity of cochlear microphonics and brain stem evoked response thresholds during post-hatching maturation of chickens ( 1 day to 3 weeks). Similarly, Rebillard and Rubel (1981), on the basis of compound action potential recordings, found no change in sensi- 
tivity for low and middle frequencies after hatching. However, in the chicken basilar papilla the centre of gravity of damaged areas of short hair cells (SHC) caused by loud sounds changed with age (Ryals and Rubel, 1985b; Rubel et al., 1984). This suggested that SHC change their preferred response frequency during post-hatching development, at least up to P30. This phenomenon was interpreted to mean that the place of analysis of given frequencies moved their positions on the basilar papilla. In these experiments, the position of damaged tall hair cells (THC), in contrast to SHC, did not change with frequency or with age. To explain this finding, Rubel et al. (1984) supposed that THC may not be part of the frequency-sclective apparatus of the papilla (Rubel et al., 1984). As shown previously (Manley et al., 1987), this assumption is untenable Cousillas and Rebillard (1985) also found a shift in the position of damaged SHC regions in the chicken with age, but the shift was restricted to developmental stages before age $\mathrm{P} 2$. There are thus a number of discrepancies in the literature concerning possible changes in the functional properties of the hearing organ of the chicken during development. 'Thus, some questions relating to the development of hearing in the chick have not yet been definitively answered, partly due to a lack of physiological data.

There are very few normative data on the response properties of nerve fibres of the chicken cochlea. Although there have been extensive anatomical and functional studies of the maturation of the chicken auditory system, only one single-unit study has been published. Staining primary afferent nerve fibres of two-day-old (P2) and three-week-old (P21) chickens and tracing them to their origins in the auditory papilla, we demonstrated that the frequency-place map of THC and their associated afferent fibres does not change during this period of development (Manley et al., 1987). The present study was carried out in order to provide data on the activity of chicken auditory afferents and to examine this activity in animals of two age groups with respect to possible changes in physiological parameters over time. The present paper reports on the spontaneous and evoked activity patterns of single auditorynerve fibres of $\mathrm{P} 2$ and $\mathrm{P} 21$ chickens.

\section{Materials and Methods}

The present study was carried out on 53 male chickens (Gallus gallus domesticus, selected white leghorn breed). Of these, 29 were P1.6 \pm 1.1 ('P2') and 24 $\mathrm{P} 21.5 \pm 3.5$ ('P21'). The animals were anaesthetized with sodium pentobarbital $(8 \mathrm{mg} / \mathrm{kg}$ for P2 animals, 14 $\mathrm{mg} / \mathrm{kg}$ for $\mathrm{P} 21)$ and chloralhydrate $(113 \mathrm{mg} / \mathrm{kg}$ and $210 \mathrm{mg} / \mathrm{kg}$, respectively) and warmed by a heating blanket to $37 \pm 1^{\circ} \mathrm{C}$. After opening an abdominal air sac, they werc respirated via a tracheal cannula (after the method of Schwartzkopff and Bremond, 1963) with a continuous stream of moist air (flow rates of $\mathrm{P} 2$ : 200-400 and P21: $200-600 \mathrm{ml} / \mathrm{min}$ ). The animals were also given an injection of Atropin $(0.025-0.05 \mathrm{mg}$ ) every 1.5 to $2 \mathrm{~h}$. All experiments were carried out in acoustically- and electrically-shielded chambers.

The cochlear ganglion was exposed via the dorsolateral approach developed for the starling (Manley and Leppelsack, 1977; Manley et al., 1985). Skin and muscle over the rostro-lateral portion of one side of the skull were opened and moved to the side. The thin bone over the middle-ear cavity was then opened, after which it is possible to see the oval and round windows of the cochlea. A small opening in the thin wall of the Recessus scala tympani was carefully made, taking care to avoid pulling on the membranous laryrinth below and avoiding blood vessels as far as possible. Once the membrane over the Recessus has been opened, much of the cochlear ganglion becomes visible as a whitish patch deep in Scala tympani.

Glass micropipettes filled with $3 \mathrm{M} \mathrm{KCl}$ or $10 \%$ HRP in tris buffer were used to record from afferent nerve fibres of the cochlear ganglion of both age groups of chickens. The electrodes were advanced using a combination of a hydraulic microdrive and a piezostepper device. Auditory units were detected by their spontaneous activity or by their response to a whitenoise search stimulus or to tone bursts, following which they were physiologically characterized. For this purpose, we determined threshold-response curves for the individual auditory units using either audiovisual criteria $(50 \mathrm{~ms}$ tones, rise-fall time $5 \mathrm{~ms}, 4 / \mathrm{s}$ ) or a computer-controlled procedure. 'The latter determined response rates for a matrix of stimuli (up to 30 frequencies and 18 sound pressure levels, $100 \mathrm{~ms}, 5 \mathrm{~ms}, 4 / \mathrm{s}$, repeated at least once). From these matrices, isorate curves were calculated. The excitatory tuning curve was taken as the isorate curve drawn using the lowest rate criterion which still gave a smooth curve. The most sensitive point on these $\mathrm{V}$-shaped tuning curves was accepted as the characteristic frequency (CF).

Frequency-threshold tuning curves were analyzed to determine the slopes of the low and high-frequency flanks (between 3 and $23 \mathrm{~dB}$ above CF threshold), the $Q_{10 \mathrm{~dB}}$ sharpness coefficient and for the presence of a break in the slope on the low-frequency flank. Intensity-rate $(\mathrm{I} / \mathrm{O})$ functions were studied both from taped series of responses to repeated tone bursts and from the response matrices used in tuning-curve determination using the frequency at or closest to the CF, a matrix frequency closest to 0.25 octaves below $\mathrm{CF}$ and one closest to 0.3 octaves above CF. In both age groups, not all cells reached saturation responses for frequencies below and above the CF even at the highest sound-pressures used. In order to maximize the 
number of cells for which $\mathrm{I} / \mathrm{O}$ function slope data could be obtained, however, we analyzed all cells where saturation was reached at the CF. Thus, although the data given in Table I for maximal rates and dynamic ranges below and above $\mathrm{CF}$ are on average slightly lower than they would be had all cells reached full saturation at all frequencies (see also Fig. 7), the data are directly comparable between age groups. These data are thus presented mainly with the intention of investigating developmental changes. The data on the slopes of $\mathrm{I} / \mathrm{O}$ functions are independent of saturation.

During some of the experiments described here, an attempt was made to stain one or two fibres per animal by iontophoretically injecting HRP, in order to localize their terminations in the papilla. The results of these stains, describing the stable tonotopic organization of the tall hair cells in the chicken papilla between the ages of $\mathrm{P} 2$ and $\mathrm{P} 21$, have been described in an earlier paper (Manley et al., 1987).

The frequency-tuning matrix was examined for the presence of single-tone rate suppression (STRS, primary suppression). In some cases, the matrix was also collected while simultaneously presenting a second, continuous tone of a frequency at or near the $\mathrm{CF}$ in order to examine the response matrix for two-tone rate suppression effects (TTRS). In addition, we recorded spontaneous activity and responses to pure-tone bursts on analog tape for off-line computer analysis. Spontaneous activity on tape was analyzed for the rate, the dead time and modal interval and for the presence of preferred intervals using time-interval histograms collected with a fine time resolution (from taped data, a minimum of 2000 intervals was analyzed using $0.1-1.2$ ms bins). Histograms showing preferred intervals were examined both with respect to their mode, but also to the preferred interval lengths as given by an analysis of the 'basic' interval (Manley et al., 1985). The basic interval is the mean of the interval lengths given by half the total interval to the second peak, one-third of the total interval to the third peak, etc.

Data sets from the two age groups (Table I) were compared using statistical tests of the SPSS/PC + package (Mann-Whitney U -Wilcoxon Rank Sum W test, Friedman two-way ANOVA test). In Table I, we compare the data from auditory-nerve fibres that describe the characteristics of the tuning curves (TC), the

TABLE I

COMPARISON OF TUNING-CURVE, SATURATED I/O-FUNCTION AND SPONTANEOUS DATA FRUM P2 AND P21 CHICKS (NONPARAMETRIC TESTS, MANN-WHITNEY U-WILCOXON RANK SUM W). I/O, INPUT-OUTPUT; TIH, TIME-INTERVAL HISTOGRAM

\begin{tabular}{|c|c|c|c|c|c|c|c|c|c|c|c|}
\hline \multirow{2}{*}{$\begin{array}{l}\text { Parameter } \\
\text { Age Group }\end{array}$} & \multirow[t]{2}{*}{ Unit } & \multicolumn{4}{|c|}{ Mean $( \pm S D)$} & \multirow{2}{*}{$\begin{array}{l}\Delta \% \text { mean } \\
\text { P2 to P21 }\end{array}$} & \multicolumn{2}{|l|}{ Range } & \multicolumn{2}{|l|}{$N$} & \multirow{2}{*}{$\begin{array}{l}\text { Signif. } \\
5 \%- \\
\text { Level }\end{array}$} \\
\hline & & $\mathrm{P} 2$ & & P21 & & & $\overline{\mathrm{P} 2}$ & $\mathrm{P} 21$ & $\overline{\mathrm{P} 2}$ & $\overline{\mathrm{P} 21}$ & \\
\hline Tuning-curve CF & $\mathrm{Hz}$ & 872.9 & $( \pm 650.8)$ & 884.1 & $( \pm 592.1)$ & +1 & $70.0-2640.0$ & $185.0-3303.0$ & 249 & 145 & n.s. \\
\hline TC Threshold & dB SPL & 56.9 & $( \pm 16.6)$ & 54.7 & $( \pm 17.1)$ & -4 & $18.0-95.0$ & $20.0-107.0$ & 249 & 145 & n.s. \\
\hline $\mathrm{TC} Q_{10 \mathrm{~dB}}$ & Value & 3.4 & $( \pm 1.9)$ & 3.2 & $( \pm 1.7)$ & -6 & $0.8-15.0$ & $0.8-\quad 10.2$ & 132 & 127 & n.s. \\
\hline TC HF-Slope & dB/Octave & 71.8 & $( \pm 34.7)$ & 76.9 & $( \pm 46.9)$ & +7 & $20.0-219.0$ & $21.0-238.0$ & 108 & 92 & n.s. \\
\hline TC LF-Slope & $\mathrm{dB} /$ Octave & 62.7 & $( \pm 40.1)$ & 78.1 & $( \pm 68.5)$ & +24 & $8.0-270.0$ & $19.0-570.0$ & 112 & 100 & n.s. \\
\hline TC L.F-Slope break & Oct re. CF & -0.74 & $( \pm 0.35)$ & -0.62 & $( \pm 0.26)$ & -16 & $(-1.3)-(-0.2)$ & $(-1.0)-(-0.2)$ & 26 & 21 & n.s. \\
\hline I/O Min rate $\mathrm{CF}$ & $\mathrm{Sp} / \mathrm{s}$ & 26.4 & $( \pm 15.8)$ & 40.2 & $( \pm 21.0)$ & +52 & $4.9-\quad 68.7$ & $5.4-92.0$ & 28 & 40 & $*$ \\
\hline I/O Min rate LF & $\mathrm{Sp} / \mathrm{s}$ & 27.4 & $( \pm 15.0)$ & 41.5 & $( \pm 23.6)$ & +51 & $3.5-55.7$ & $4.0-101.1$ & 27 & 40 & * \\
\hline I/O Min rate $\mathrm{HF}$ & $\mathrm{Sp} / \mathrm{s}$ & 27.9 & $( \pm 18.4)$ & 40.8 & $( \pm 22.2)$ & +46 & $3.5-78.3$ & $8.4-\quad 90.5$ & 28 & 40 & $*$ \\
\hline I/O Max rate $\mathrm{CF}$ & $\mathrm{Sp} / \mathrm{s}$ & 138.9 & $( \pm 56.0)$ & 207.6 & $( \pm 84.7)$ & +49 & $31.0-254.0$ & $71.8-426.8$ & 28 & 40 & * \\
\hline I/O Max rate $\mathrm{LF}$ & $\mathrm{Sp} / \mathrm{s}$ & 128.2 & $( \pm 51.5)$ & 186.7 & $( \pm 80.4)$ & +46 & $33.0-223.0$ & $58.9-375.9$ & 28 & 40 & * \\
\hline $\mathrm{I} / \mathrm{O}$ Max rate $\mathrm{HF}$ & $\mathrm{Sp} / \mathrm{s}$ & 116.1 & $( \pm 49.4)$ & 172.0 & $( \pm 87.2)$ & +48 & $27.3-228.0$ & $61.2-414.3$ & 28 & 40 & * \\
\hline I/O Dyn range $C F$ & $\mathrm{Sp} / \mathrm{s}$ & 112.6 & $( \pm 47.6)$ & 167.5 & $( \pm 79.7)$ & +49 & $19.8-196.6$ & $42.2-397.0$ & 28 & 40 & * \\
\hline I/O Dyn range LF & $\mathrm{Sp} / \mathrm{s}$ & 104.8 & $( \pm 52.7)$ & 145.2 & $( \pm 79.6)$ & +39 & $19.6-233.9$ & $26.6-350.2$ & 28 & 40 & $*$ \\
\hline $\mathrm{I} / \mathrm{O}$ Dyn range $\mathrm{HF}$ & $\mathrm{Sp} / \mathrm{s}$ & 88.2 & $( \pm 41.9)$ & 131.2 & $( \pm 83.3)$ & +49 & $14.8-160.7$ & $26.3-380.3$ & 28 & 40 & * \\
\hline $\mathrm{I} / \mathrm{O}$ Dyn range $\mathrm{CF}$ & $\mathrm{dB}$ & 45.7 & $( \pm 13.6)$ & 38.5 & $( \pm 11.2)$ & -16 & $19.6-78.7$ & $12.1-69.4$ & 28 & 40 & $*$ \\
\hline I/O Dyn range LF & $\mathrm{dB}$ & 43.5 & $( \pm 13.2)$ & 35.5 & $( \pm 12.2)$ & -21 & $17.9-64.0$ & $14.8-60.7$ & 28 & 40 & * \\
\hline I/O Dyn range $\mathrm{HF}$ & $\mathrm{dB}$ & 39.0 & $( \pm 13.8)$ & 32.6 & $( \pm 11.8)$ & -16 & $10.1-64.0$ & $14.0-59.8$ & 28 & 40 & * \\
\hline I/O Slope CF & $\mathrm{Sp} / \mathrm{s} / \mathrm{dB}$ & 3.0 & $( \pm 1.1)$ & 5.6 & $( \pm 3.6)$ & +87 & $1.1-$ & $1.4-20.2$ & 28 & 40 & $*$ \\
\hline I/O Slope LF & $\mathrm{Sp} / \mathrm{s} / \mathrm{dB}$ & 2.7 & $( \pm 1.1)$ & 4.8 & $( \pm 2.7)$ & +78 & $0.9-$ & $0.9-13.2$ & 28 & 40 & $*$ \\
\hline I/O Slope HF & $\mathrm{Sp} / \mathrm{s} / \mathrm{dB}$ & 2.4 & $( \pm 1.1)$ & 4.2 & $( \pm 2.5)$ & +75 & $0.6-$ & $0.8-11.3$ & 28 & 40 & $*$ \\
\hline TIH Spont rate & $\mathrm{Sp} / \mathrm{s}$ & 20.5 & $( \pm 10.1)$ & 22.9 & $( \pm 9.8)$ & +12 & $3.0-42.7$ & $13.3-50.8$ & 53 & 29 & n.s. \\
\hline TIH Dead time & $\mathrm{ms}$ & 1.6 & $( \pm 0.4)$ & 1.6 & $( \pm 0.6)$ & +1 & $1.1-\quad 2.9$ & $1.0-\quad 3.5$ & 49 & 30 & n.s. \\
\hline TIH Mode & $\mathrm{ms}$ & 4.7 & $( \pm 4.2)$ & 4.3 & $( \pm 4.8)$ & -9 & $1.4-20.3$ & $1.2-25.0$ & 50 & 30 & n.s. \\
\hline
\end{tabular}


minimal and maximal rates of the $1 / O$ functions, the dynamic ranges of the $\mathrm{I} / \mathrm{O}$ functions expressed in $\mathrm{dB}$ and in spikes/s, the slopes of the $\mathrm{I} / \mathrm{O}$ functions in spikes $/ \mathrm{s} / \mathrm{dB}$ and the spontaneous activity.

\section{Results}

We report data from recordings of 394 primary afferent fibres. Whereas no statistically-significant differences were observed between data describing the frequency tuning curves from animals belonging to the two age groups, differences were found in the parameters of the intensity functions. In most figures, however, data for the two age groups are presented using different symbols.

As reported for the starling and pigeon (Manley et al., 1985; Schermuly and Klinke, 1990), a number of fibres in the cochlear ganglion do not respond to sound with a rate increase, although some show phase-locking to tones. In a separate study, we have examined the spontaneous activity of some of these fibres in the chicken. Most fibres showing no responses whatever to sound were traced to terminations in the lagena macula; a very few innervated the apical basilar papilla (Haeseler et al., 1989; Manley et al., 1991).

\section{Tone-evoked activity: tuning curves}

The afferent fibres encountered in the cochlear ganglion were clearly tonotopically organized. Fibres within single penetrations were encountered with a systematic frequency organization in depth very similar to that described for the starling cochlear ganglion (Manley et al., 1985), high-CF fibres being found basally, low-CF fibres apically. As it is difficult to place electrodes in the extreme basal end of the ganglion, the absence of really high-frequency fibres from our sample is not surprising. In addition, in P21 chickens, the low-frequency end of the ganglion is covered by a sheet of connective tissue of variable size; this makes it very difficult in animals of this age group to contact fibres with $\mathrm{CF}$ below about $0.2 \mathrm{kHz}$. Apart from these difficulties, the distribution of $\mathrm{CF}$ among fibres of the different age groups of animals is very similar (Fig. 1).

Tuning curves complete enough to permit measurement of the slopes of both flanks were obtained from 200 fibres. Most fibres showed fairly simple V-shaped tuning curves (Fig. 2). The fibre CF ranged from 0.07 to $3.3 \mathrm{kHz}$ and their thresholds at $\mathrm{CF}$ ranged from below 20 to over $100 \mathrm{~dB}$ SPL (Fig. 1). In individual animals, the range of thresholds was maximally $59 \mathrm{~dB}$. There was no statistically-significant difference between the threshold distributions of pooled data from P2 and P21 animals (Table I). However, when the threshold data were divided into frequency blocks, the mean thresholds of fibres of $\mathrm{CF}$ above $1.5 \mathrm{kHz}$ from $\mathrm{P} 2$
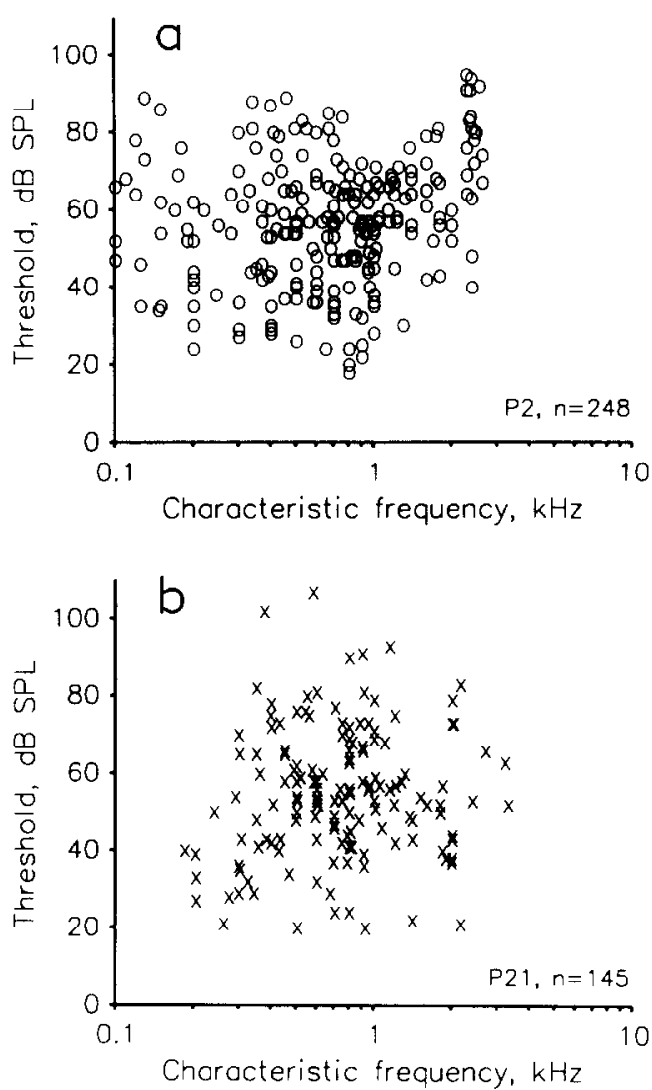

Fig. I. (a, b). The distributions of characteristic frequencies and thresholds for cochlear ganglion neurones of (a) P2 animals and (b) P21 animals. One cell with a CF of $0.07 \mathrm{kHz}$ has been omitted from (a). The threshold scatter is larger in pooled data than in individual animals (see text). There is no significant difference in threshold distribution between the pooled data in (a) and (b) but the poorer threshold of high-frequency tuning curves $(\mathrm{CF}>1.5 \mathrm{kHz}$ ) in $\mathrm{P} 2$ cells is significantly different to that of P21 animals (see Table l).

animals were significantly less sensitive (10 to $15 \mathrm{~dB})$ than those from P21 animals (compare Figs. 1 and 2).

The slopes of the low- and the high-frequency flank tend to differ for each fibre, although both tend to

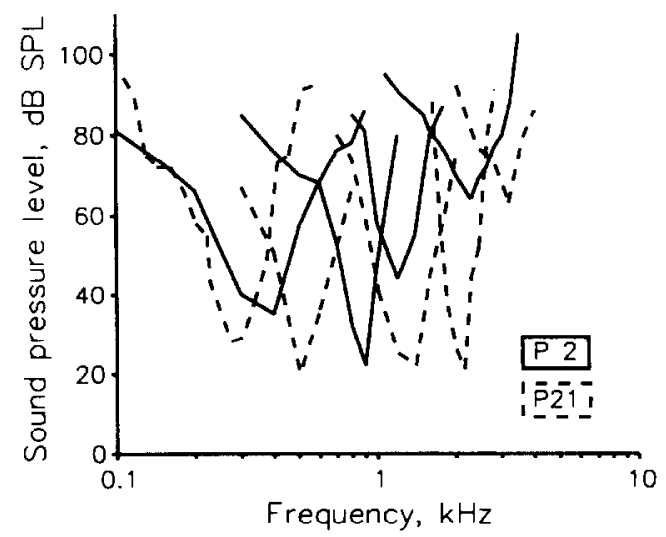

Fig. 2. Representative frequency-threshold tuning curves for cochlear ganglion neurones of P2 (continuous lines) and P21 (dashed lines) animals. 
increase with CF (Fig. 3 a,b). There was no consistent asymmetry to the tuning curves between 3 and $23 \mathrm{~dB}$ above CF threshold as seen in mammals; fibres with a steeper low-frequency flank were almost as numerous as those with a steeper high-frequency flank (Fig. 3c). In both $\mathrm{P} 2$ and $\mathrm{P} 21$ animals, $36 \%$ of tuning curves were steeper on the low-frequency flank (Fig. 3d). There was no strong trend of tuning-curve symmetry across the $\mathrm{CF}$ range, although in animals of both age groups, fibres of $\mathrm{CF}>1.5 \mathrm{kHz}$ had tuning curves with steeper high-frequency flanks (Fig. 3d). No significant differences were found in the tuning-curve parameters tested for $\mathrm{P} 2$ and $\mathrm{P} 21$ animals.

About a quarter of tuning curves over the whole CF range in both age groups showed an obvious break to lower slopes on the low-frequency flank (Fig. 2). This break occurred on average at about 0.7 octaves below $\mathrm{CF}$ in both P2 and P21 animals (Table I) and at a level between about 65 and $90 \mathrm{~dB}$ SPL, independently of the actual fibre threshold at CF (Fig. 4a). The dB-distance from the level of the CF threshold to the level of the break in slope is therefore small in higher-threshold fibres. Thus there is a clear relationship between the SPL of the CF threshold and the distance in $\mathrm{dB}$ from CF threshold to the level of the slope break (Fig. 4b).

Tuning-curve sharpness, expressed as the $Q_{10 \mathrm{~dB}^{-}}$ value, is a common way of describing the frequency selectivity of auditory units. Although there is a large spread of $Q_{10 \mathrm{~dB}}$ for fibres of both age groups, the mean $Q_{10 \mathrm{~dB}}$ value at a particular fibre $\mathrm{CF}$ increases with $C F$ in a similar way in both age groups (Fig. 5) and does not differ statistically for the two ages (Table I). Within each age group, significant linear correlations exist between the CF and the $Q_{10 \mathrm{~dB}}$ value, between the $\mathrm{CF}$ and the slopes of the tuning curve flanks and between the slopes of the tuning curve flanks of each side. However, there is no statistical difference between tuning curves from animals of the two age groups with respect to the means of the CF, thresholds, $Q_{10 \mathrm{~dB}}$ and the slopes of the high- and low-frequency flanks (Table I).

With regard to tuning curves, there are thus no
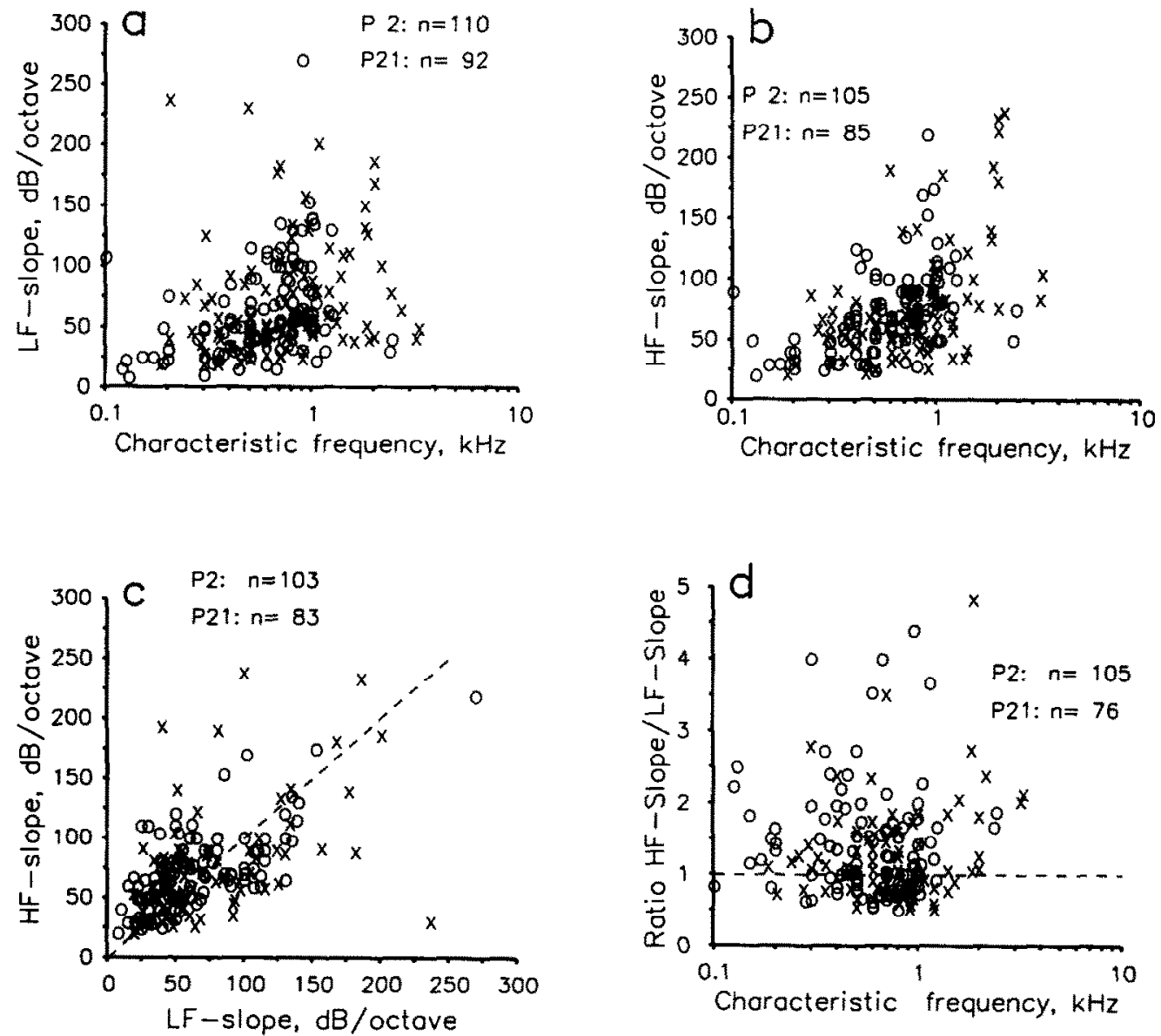

Fig. 3. (a, b, c, d) Characteristics of the slopes of the low-frequency (LF) and high-frequency (HF) flanks of the tuning curves measured in both age groups. The slopes are measured between 3 and $23 \mathrm{~dB}$ above CF threshold. (a) LF slope as a function of CF; (b) HF slope as a function of CF; (c) a direct comparison of LF and HF slopes. The dashed line shows a 1:1 relationship between the two variables. There is no consistent asymmetry of tuning curves; (d) The ratio of the slopes of the high- to the low-frequency flanks of the tuning curves as a function of fibre CF. Symbols: open circles for data from P2 animals, crosses: P21 animals. The data from the two age groups do not differ (see Table 1). 

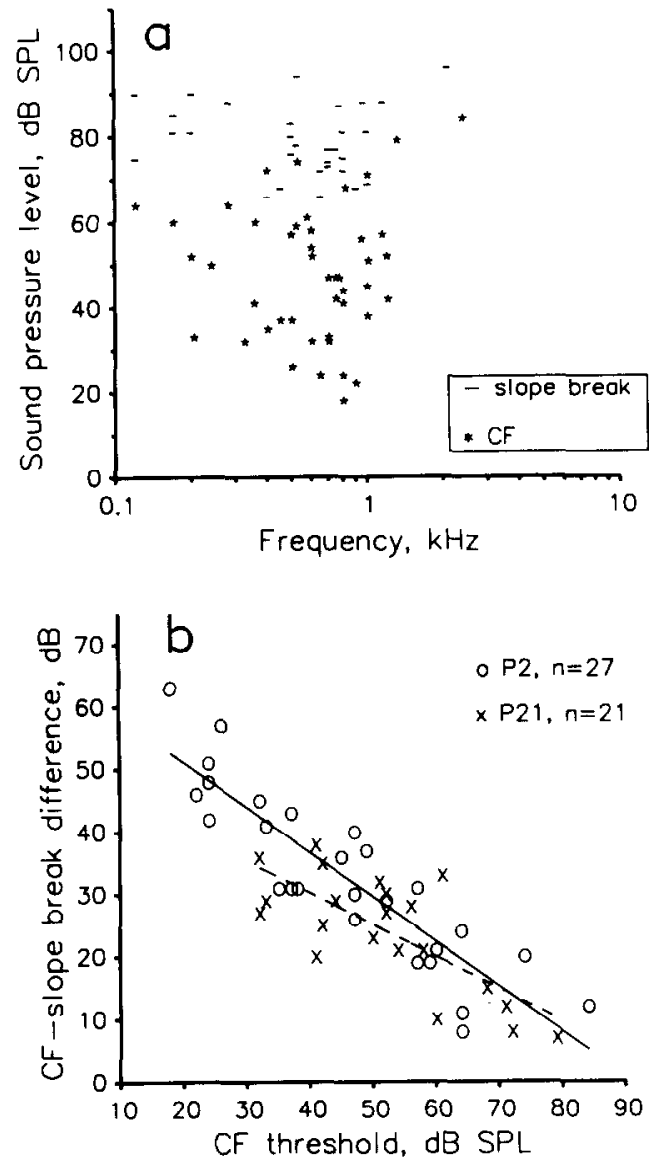

Fig. 4. (a, b). Features of the break in slope on the low-frequency flank of tuning curves. (a) The cell threshold at CF (asterisks) compared to the SPL at which the slope-break occurs (dashes), showing the much smaller variability of the latter. Data from the two age groups have been combined (no significant difference, see Table I) in order to reduce confusion due to more symbol types. (b) The dependence of the difference in threshold between a given cell's CF and the SPL of its slope break as a function of CF threshold, symbols as in Fig. 3. The lines represent linear regressions on the data for P2 (continuous line) and P21 (dashed line) animals. P2: $N=27, \mathrm{r}=$ $-0.79, P<0.001 ; \mathrm{P} 21: N=21, \mathrm{r}=-0.55, P<0.01)$

significant changes between the ages $\mathrm{P} 2$ and $\mathrm{P} 21$. The only difference seen is an improvement in thresholds of fibres with CF above about $1.5 \mathrm{kHz}$.

\section{Discharge patterns to single tones}

Auditory-nerve fibres of the chicken responded to sound stimuli either by increasing or by decreasing their firing rate with reference to their spontaneous level. The second response type is also known as primary or single-tone rate suppression (STRS, Fig. 6b). Phase locking behaviour was not systematically investigated.

The most common response to a tonal stimulus is a tonic increase in discharge rate. With increasing sound-pressure level, the response includes an increasingly large phasic component. In some cases, the fall in rate has not reached a plateau before the stimulus is

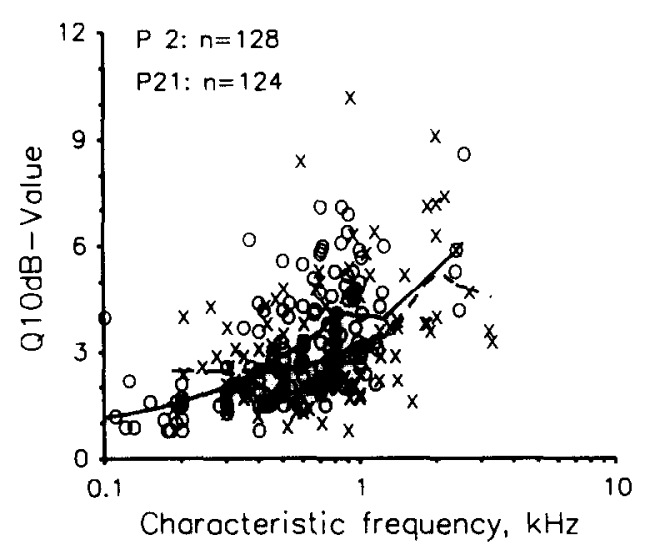

Fig. S. The $Q_{10 \mathrm{~dB}}$ sharpness coefficient as a function of the $\mathrm{CF}$ of $\mathrm{P} 2$ and P21 cells. Symbols as in Fig. 3. The grey lines indicate locallyweighted regression curves for P2 (continuous line) and P21 (dashed line) animals. There is no significant difference between the data from the two age groups (see Table I).

terminated. Except for near-threshold stimuli, the tonal response is followed at offset by a period of reduced spontaneous activity (Fig. 6a). In addition, some combinations of frequency and level induced on-off responses in the fibres. This phenomenon, which has been previously reported in other species (Gross and
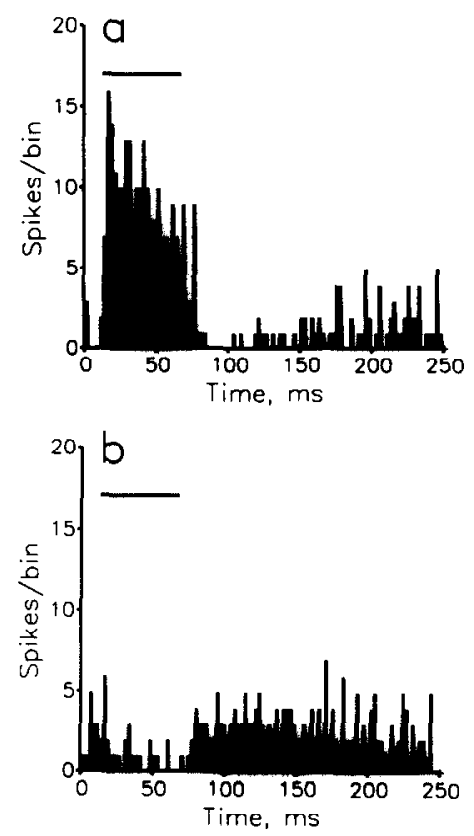

Fig. 6. (a, b) Peri-stimulus-time histograms of responses evoked in a single nerve fibre (CF $0.35 \mathrm{kHz}$ and threshold $35 \mathrm{~dB}$ SPL) by $55 \mathrm{~ms}$ tones repeated 20 times at the same frequency above the CF. In (a) the tone $(0.55 \mathrm{kHz}, 95 \mathrm{~dB} \mathrm{SPL})$ lay $12 \mathrm{~dB}$ above the rate-response threshold at this frequency. The cell shows a strongly phasic response followed by an obvious depression of the spontaneous activity. In (b) the tone level $(0.55 \mathrm{kHz}, 65 \mathrm{~dB}$ SPL) lies $18 \mathrm{~dB}$ below the rate-increase threshold, but within the primary suppression area. The cell responds to the tone burst with a reduction in the spontaneous rate followed by a small overshoot after stimulus offset. The bin width in (a) and (b) is $2.5 \mathrm{~ms}$. 

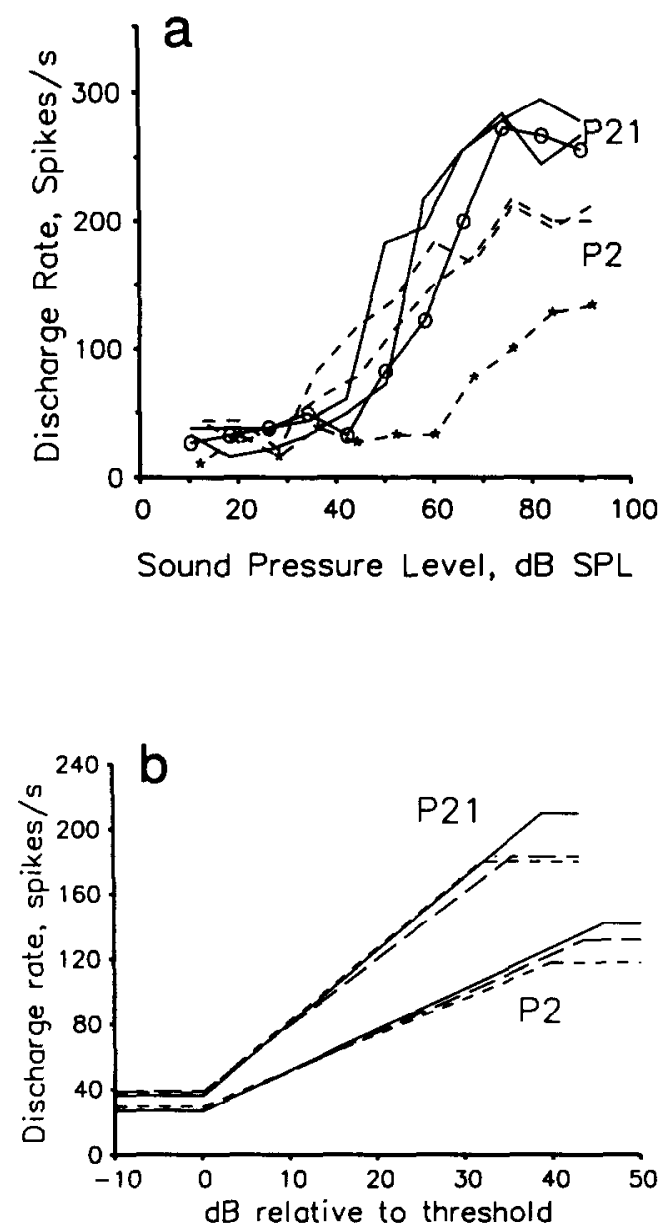

Fig. 7. (a, b) Characteristics of $I / O$ functions of both age groups for frequencies at $C F$, below and above $C F$. (a) two sets of $I / O$ functions from one P21 ganglion cell (continuous lines) and one P2 ganglion cell (dashed lines). In each set, the most sensitive I/O function is for the $C F$, the curves shown with symbols represent the data for the frequency below $\mathrm{CF}$. (b) Idealized $\mathrm{I} / \mathrm{O}$ functions drawn using the mean data for fibres in P2 $(N=18)$ and P21 $(N=21)$ animals that showed saturated $\mathrm{I} / \mathrm{O}$ functions at $\mathrm{CF}, \mathrm{LF}$ and $\mathrm{HF}$. For each age group, the $\mathrm{I} / \mathrm{O}$ function at the $\mathrm{CF}$ is shown as a continuous line, 0.25 octaves below $\mathrm{CF}$ as a long-dashed line and 0.32 octaves above $\mathrm{CF}$ as a short-dashed line. In all cases, the curves have been plotted with the respective threshold normalized to $0 \mathrm{~dB}$. The initial discharge rate at threshold represents an increase of $2 \mathrm{~dB}$ over spontaneous rate for $\mathrm{P} 2$ and $3 \mathrm{~dB}$ over spontaneous rate for P21 animals. Increasing development results in steeper slopes, smaller

dynamic ranges in $\mathrm{dB}$ and greater dynamic ranges in spikes/s.

Anderson, 1976; Hill et al., 1989a; Manley et al., 1985) was not studied systematically.

Rate-intensity functions offer a good method of examining response patterns for quantitative differences between groups of animals. For animals of both age groups, intensity $(\mathrm{I} / \mathrm{O})$ functions were measured using both $\mathrm{CF}$ tones and two other frequencies out of the tuning-curve matrix, that were on average 0.25 octaves below and 0.32 octaves above the CF (Fig. 7a). Data are included in Table $I$ for all cells in which the $\mathrm{I} / \mathrm{O}$ function at the $\mathrm{CF}$ had clearly reached the satura- tion rate. The average values plotted in Fig. 7b, however, are only for cells whose $\mathrm{I} / \mathrm{O}$ functions reached saturation at all three frequencies. An examination of all cases in which $\mathrm{I} / \mathrm{O}$ functions at all three frequencies (CF, LF, HF) were saturated (about half), however, indicated that the deviations of the summed data (all cells in which at least the CF I/O function was saturated) are less than $10 \%$ and do not always show higher values than when all data are included. Thus the conclusions reached from the data in Table I are representative.

The dynamic ranges both in spikes/s and in $\mathrm{dB}$ are not dependent on the spontaneous rate or on the cell's $\mathrm{CF}$ in either age group. In both groups of animals, neither the dynamic range as expressed in spikes/s nor the slope of the I/O functions are dependent on the cell's threshold. In both groups of animals, however, the dynamic range as expressed in $\mathrm{dB}$ is correlated with the threshold, becoming smaller at higher thresholds (P2: $N=28, \mathrm{r}=-0.45, P<0.01 ; \mathrm{P} 21: N=40$, $\mathrm{r}=-0.58, P<0.001$ ). On average, a reduction in the dynamic range of $10 \mathrm{~dB}$ results from a rise in threshold of $17 \mathrm{~dB}(\mathrm{P} 2)$ or $25 \mathrm{~dB}(\mathrm{P} 21)$.

From the individual $\mathrm{I} / \mathrm{O}$ functions, the following data points were extracted: the minimal and maximal discharge rates, the dynamic range in spikes/s (maximal-minimal values), the dynamic range in $\mathrm{dB}$ and the slopes of the $\mathrm{I} / \mathrm{O}$ function (the latter two measured between 10 and $90 \%$ of maximum rate). In $\mathrm{P} 21$ animals, the maximal discharge rates at CF $(207.6 \pm 84.7)$ are significantly higher than those of $\mathrm{P} 2$ animals at CF $(138.9 \pm 56.0$, Fig. $7 \mathrm{~b}$ and Table I). The dynamic ranges in $\mathrm{dB}$ are smaller in P21 at CF $(38.5 \pm 11.2 \mathrm{~dB})$ than in $\mathrm{P} 2$ animals at $\mathrm{CF}(45.7 \pm 13.6 \mathrm{~dB}$, Fig. $7 \mathrm{~b})$. Also, the dynamic ranges in spikes/s are greater in $\mathrm{P} 21$ animals, which is correlated with steeper slopes of the $\mathrm{I} / \mathrm{O}$ functions at $\mathrm{CF}$. The dynamic ranges and the slopes of the intensity functions in both age groups (Fig. 8) are significantly correlated. In P21 animals there is a dynamic range of about $30 \mathrm{~dB}$ independent of the dynamic range in spikes/s, but the dynamic range in $\mathrm{dB}$ in P2 animals increases with an incrcase in the dynamic range as expressed in spikes/s. Compared to P21 animals, the rate and slope data are smaller in $\mathrm{P} 2$ animals and the dynamic range in $\mathrm{dB}$ is larger in $\mathrm{P} 2$ animals at all three frequencies.

Statistical tests comparing mean data for intensity functions at the $\mathrm{CF}$ and off the $\mathrm{CF}$ in fibres for which the I/O functions were saturated at all three frequencies indicated that within age groups, the characteristics of the HF functions differ significantly from those at the CF. The characteristics of the intensity function within each tuning curve are frequency dependent. However, LF and HF do not differ within any one age group and for most data sets, the CF and LF data are not different. The exceptions to the latter statement 
are that in P21 animals, the maximal rates and the dynamic ranges in spikes/s differ for $\mathrm{CF}$ and LF functions.

Thus between the ages of $\mathrm{P} 2$ and $\mathrm{P} 21$, there are changes in the characteristics of the $\mathrm{I} / \mathrm{O}$ functions, the most obvious being a rise in the maximal discharge rates accompanied by a reduction in the dynamic range in $\mathrm{dB}$.

\section{Single- and two-tone rate suppression}

In a number of cells, the spontaneous activity was obviously suppressed by certain non-excitatory tones lying in frequency below and above the excitatory tuning curve (Fig. 9a). This primary suppression was found both in cells with and in those without preferred intervals. This effect was, however, often difficult to observe, especially in cells with lower spontaneous discharge rates and was not studied systematically. Thus it is not possible from our data to establish the percentage of cells showing this phenomenon. There was no consistent behaviour with regard to the low-and highfrequency single-tone suppressive areas being more sensitive. No differences were seen between the two groups of animals: the characteristics of single-tone suppression did not differ and all cells examined in detail in animals of both ages (19 cases), also showed two-tone suppression phenomena (Fig. 9b).

\section{Spontaneous activity}

There were no strong differences between spontaneous activity patterns in fibres of the two animal

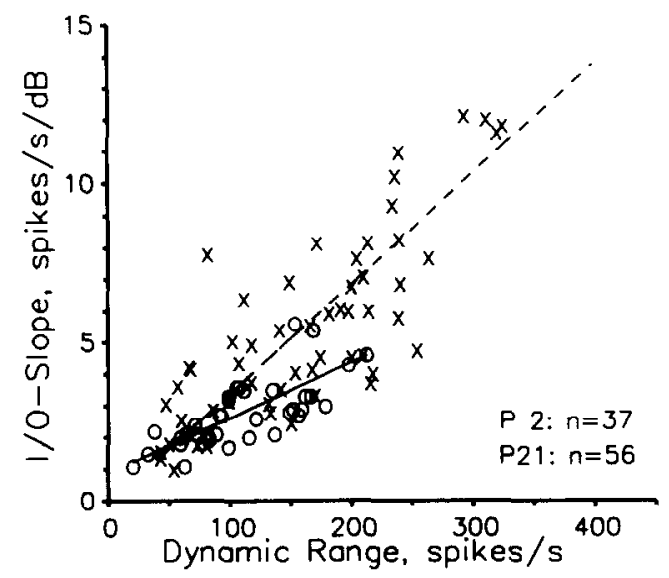

Fig. 8. The slope of intensity functions at the respective $C F$ as a function of their dynamic range expressed as the rate increase (spikes/s). Simple regressions on the data are shown as a continuous black line ( $\mathrm{P} 2$ data; $\mathrm{r}=0.741, P<0.001)$ and a dashed line ( $\mathrm{P} 21$ data; $\mathrm{r}=0.822, P<0.001)$. The slopes of $\mathrm{I} / \mathrm{O}$ functions of $\mathrm{P} 21$ animals are on average higher for all dynamic ranges. These data indicate that in P21 animals, the increase in slope is partly achieved by reduced dynamic ranges in $\mathrm{dB}$ as compared to $\mathrm{P} 2$ animals. In $\mathrm{P} 2$ animals, the dynamic range in $\mathrm{dB}$ increases disproportionately in cells with higher discharge rates, while it is near $30 \mathrm{~dB}$ for P21 animals, independently of the spike rate increase.
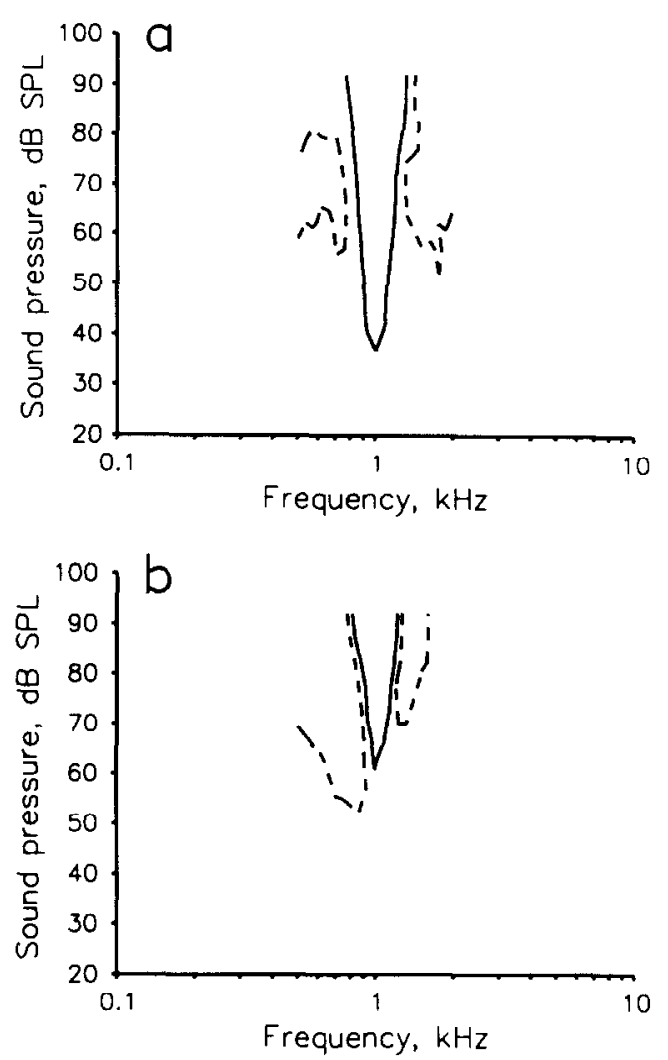

Fig. 9. (a, b) Tuning curves from the same cell with a spontaneous rate of 28 spikes/s under two stimulus conditions. In (a) the continuous line is the normal, excitatory tuning curve (iso-rate criterion 40 spikes/s). At frequencies below and above the tuning curve are drawn iso-rate tuning curves (criterion 26 spikes/s) as dashed lines, for responses indicating primary suppression (that is, a fall in discharge rate below spontaneous rate). These curves are open to the side due to the limited data at low and high frequencies. In (b) the same cell was exposed to a continuous $C F$ tone at about $10 \mathrm{~dB}$ above threshold and the response matrix of the additional pulsed tones sampled. The excitatory tuning curve (iso-rate criterion 78 spikes/s) is displaced upwards about $20 \mathrm{~dB}$ due to the increased background response to the $\mathrm{CF}$ tone. The dashed tuning curves at higher and lower frequencies are iso-rate curves (criterion 65 spikes/s) indicating TTRS thresholds.

groups. Two types of spontaneous activity were encountered in the cochlear ganglion: irregularly- and regularly-firing fibres. All regularly-firing and some irregularly-active fibres did not respond to sound. All auditory fibres showed an irregular spontaneous activity. In this case, auditory means that the fibres responded with a rate increase to test frequencies in the range of 0.020 to $5 \mathrm{kHz}$ at SPL generally up to $95 \mathrm{~dB}$ SPL. The characteristics and origins of some of the other fibre types are described separately (Haeseler et al. 1989; Manley et al., 1991).

In both P2 and P21 animals, there was an essentially unimodal distribution of spontaneous rates (Fig. 10). The mean spontaneous discharge rate was similar in both age groups, the range for $\mathrm{P} 2$ animals being 3.0 to 42.7 (mean 20.5 spikes/s) and for P21 animals 13.3 to 


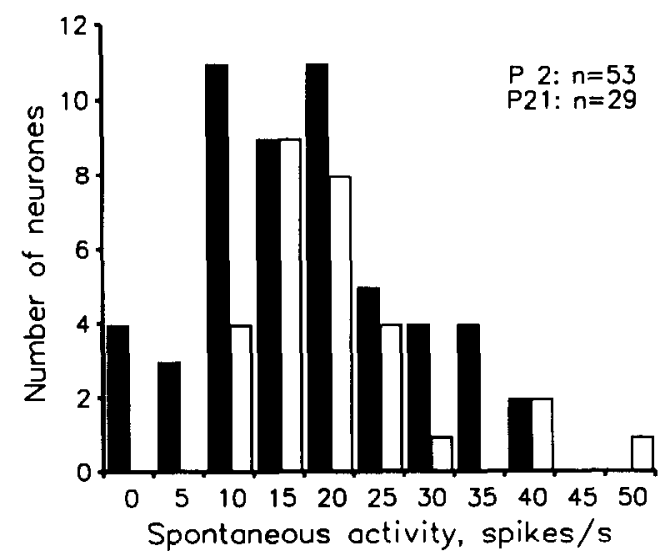

Fig. 10. A histogram of the distribution of spontaneous rates in $P 2$ animals (solid columns) and P21 animals (open columns) using a bin width of 5 spikes $/ \mathrm{s}$. The pooled data do not differ significantly (see Table I).
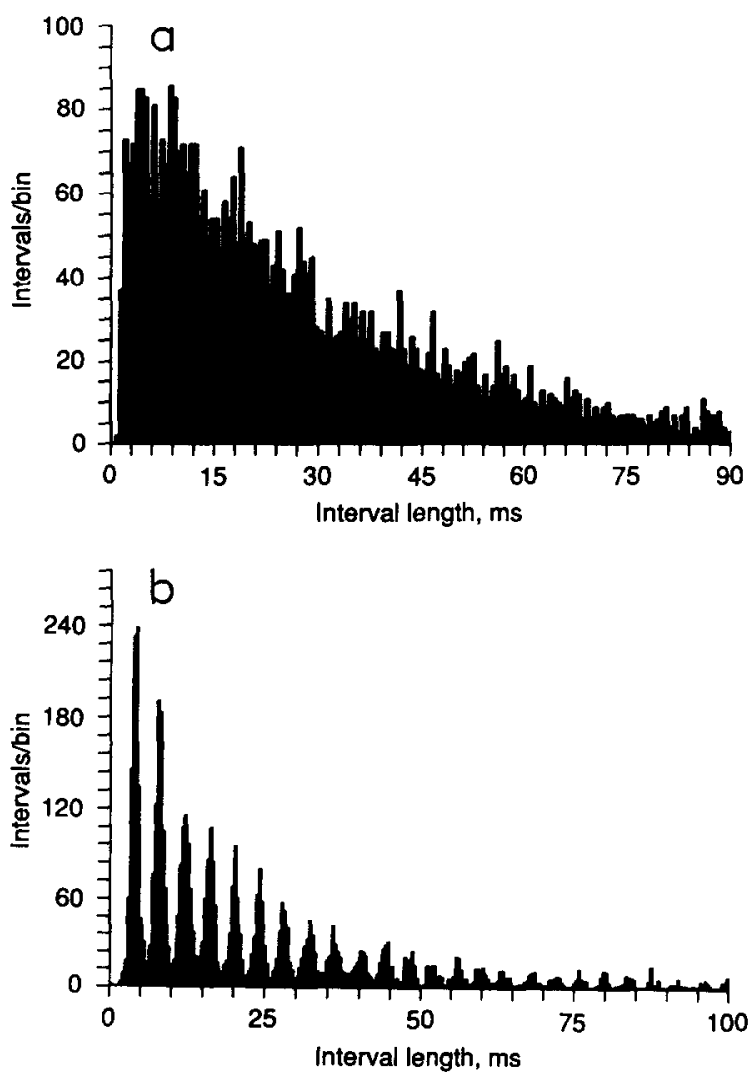

Fig. 11. (a, b) Time-interval histograms of spontaneous activity for two auditory cells of the chick cochlear ganglion. Although both cells show a generally irregular activity pattern, only the TIH of the cell in (a) shows the typical quasi-Poisson distribution of intervals (note the ordinate has a linear scale). The cell in (b) shows very prominent preferred intervals whose 'basic interval' is about $4 \mathrm{~ms}$. The peaks of the preferred intervals are present up to intervals of at least $80 \mathrm{~ms}$. In (a) 4238 intervals are displayed for a discharge rate of 30.6 spikes $/ \mathrm{s}$ using a $0.6 \mathrm{~ms}$ bin width. The respective numbers for (b) are: 5198 intervals, 32.9 spikes $/ \mathrm{s}, 0.4 \mathrm{~ms}$ bin width.
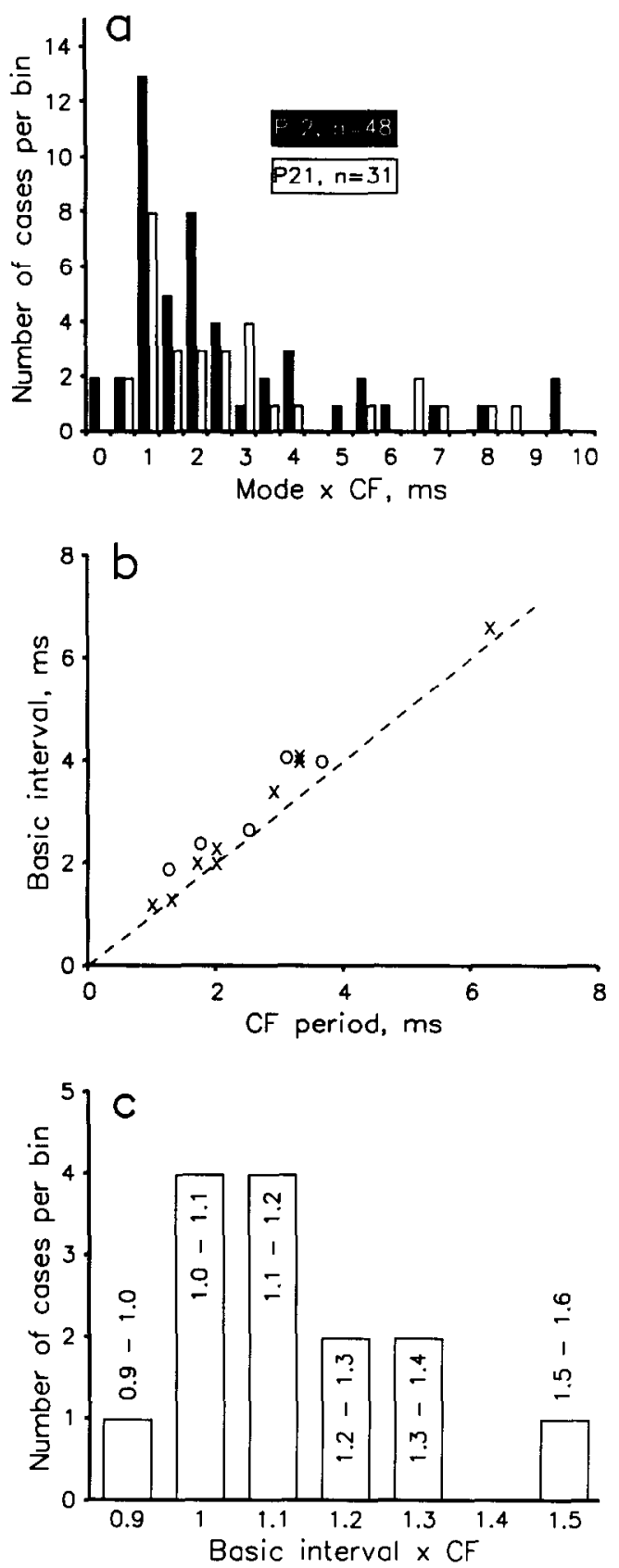

Fig. 12. (a, b, c) An analysis of the mode of time-interval histograms (TIH) and the basic interval of any preferred intervals present in TIH as a function of the respective cell CF. The basic interval is the average of the interval of the first peak, half the interval of the second peak, one-third the interval of the third peak, etc. (a) The distribution of the product of the mode and cell CF (a value of 1 indicates that mode equals CF-period). (b) A comparison of the period of the $\mathrm{CF}$ and the basic interval in cells showing prominent preferred intervals in the TIH. For 12 of the 14 cells the basic interval is longer than the CF period. (c) The product of the basic interval and the respective cell $\mathrm{CF}$ is on average slightly more than the value of 1 .

50.8 (mean 22.9 spikes/s, see Table I). The spontaneous rate was not correlated with the fibre $\mathrm{CF}$ and only weakly (negatively) correlated with the threshold 
to tones at the CF and this only in $\mathrm{P} 2$ animals $(N=53$, $\mathrm{r}=-0.36, P<0.01$ ).

The spontaneous activity patterns observed in timeinterval histograms were similar to those of the starling (Manley and Gleich, 1984; Manley et al., 1985). In general, the spike intervals showed a quasi-Poisson distribution (Fig. 11a). However, prominent preferred intervals were seen in $15 \%$ of time-interval histograms, but only for cells whose $\mathrm{CF}$ was $1 \mathrm{kHz}$ or below. In some cases, peaks were discernable up to long interval lengths (Fig. 11b). An analysis of the modal intervals shows a large number of cases in which the interval of the TIH mode is longer than the period of the cell's CF (Fig. 12a). In a few cases, the mode of a TIH showing preferred intervals lay not at the first peak, but at the second or third peak. Similarly to the situation with regard to the TIH mode, an analysis of 'basic intervals' ( $N=14$, calculated according to Manley et al., 1985) of TIH showing several strong preferred-interval peaks revealed that these basic intervals tend to be somewhat longer (on average 18\% longer) than the CF-period (Fig. 12b,c)

\section{Discussion}

Data from single auditory-nerve fibres in birds are available for the pigeon (Gross and Anderson, 1976; Hill et al., 1989a; Sachs et al., 1974; Temchin, 1980, 1988), for the starling (Manley, 1979; Manley and Gleich, 1984; Manley et al., 1985), for the redwing blackbird (Sachs et al., 1980) and for the chicken (Manley et al., 1987). In the present data, the recessus of the scala tympani was opened and fibres recorded directly in the cochlear ganglion. This is a rapid technique, although the bone is more vascularized in these young animals than in the adult starling, which can lead to more bleeding. In addition, a fine capillary vessel suspended in the scala tympani can lead to problems of electrode placement. In the chicken also, this surgical approach does not allow easy access to the high-frequency end of the ganglion. This basal end can also be affected by the surgery due to its proximity to the opening in the bone.

\section{Tuning of single fibres}

The data reported here describe the activity of single auditory-nerve fibres, the great majority of which synapse with tall hair cells only (Manley et al., 1987, 1989). In the basal half of the chicken's papilla, most short hair cells do not receive any affercnt innervation (Fischer et al., in preparation). In common with all other vertebrate auditory fibres, the single units of the avian auditory nerve are highly frequency selective. The tuning curves are, if anything, more sharply tuned than those of mammals in the equivalent frequency range (Manley et al., 1985; Sachs et al., 1980), at least when measured as the sharpness of the tip region $\left(Q_{10 \mathrm{~dB}}\right)$. When compared to those of a mammal, however, avian tuning curves do not show such a consistent asymmetry, with the high-frequency flank being steeper than the low-frequency flank.

Only about $25 \%$ of the chicken fibres of animals of both age groups showed a clear break in slope on the low-frequency flank. These slope breaks were, however, not as consistently found and nowhere near as prominent as the low-frequency 'tails' of higherfrequency mammalian nerve fibres. Nevertheless, the frequencies at which the break in slope occurred bore a clear relationship to the cell CF and the slope break always occurred within a relatively narrow range of SPL (Fig. 4a). It is likely that these details of the shape of the tuning curves are related to the macro-mechanical analysis of frequency in the avian cochlea. Further discussion on these aspects must await the availability of comparative data from other avian species.

Except that there is a paucity of data from very low-CF fibres for the older animals (due to their inaccessibility), the distribution of CF was essentially the same for both age groups. In both cases also, there was a wide range of fibre thresholds even within individual animals. Single-fibre staining in the starling papilla suggests that there is a gradient of sensitivity of afferent fibres, those innervating more neural hair cells being more sensitive (Gleich, 1989; Manley et al., 1989). The threshold in the starling rises across the epithelium at the rate of about $6 \mathrm{~dB}$ /hair cell, such that hair cells that are in the middle of the epithelium have thresholds of more than 80 or $90 \mathrm{~dB}$ SPL (Gleich, 1989; Manley et al., 1989). We have previously shown that in the chicken also, almost all active fibres in the auditory nerve innervate only one single tall hair cell (Manley et al., 1987). It appears that these THC fibres are the only or at least the main carriers of auditory information from the inner ear to the brain. If the samc threshold-hair cell pattern as reported in the starling is present in chickens, then most of the wide range of fibre thresholds could be explained on this basis. Of course, it is not possible to exclude other factors, such as damage to the cochlea, as causes of reduced sensitivity in some cells.

Despite this caveat, it seems likely that the 10-15 dB threshold difference between the two age groups for fibres with $\mathrm{CF}>1.5 \mathrm{kHz}$ is real. It matches well the difference for frequencies in this range in thresholds of cochlear-nucleus evoked-response audiograms measured for 1- and 21-day old chickens (Saunders et al., 1973). In that study, the thresholds showed only a slight improvement in sensitivity over this time period for frequencies below about $1 \mathrm{kHz}$, but a 10 to $20 \mathrm{~dB}$ improvement above $1 \mathrm{kHz}$. This also correlates with the data of Lippe and Rubel (1985) and Rebillard and 
Rubel (1981) and suggest that, at age P2, the ontogeny of sensitivity at the highest frequencies is not quite complete, even though the tuning is mature. Saunders et al. (1986) demonstrated the presence of strong changes in the properties of the chicken middle ear before hatching. Even following hatching, there is a gradual change in middle-ear admittance up to 10 weeks post-hatching. It is likely that all of the threshold difference above $1 \mathrm{kHz}$ evident in our data is due to an improvement in middle-ear transmission. It should not be forgotten, however, that in the developing chicken, efferent fibres are adult-like only 1 week after hatching (Whitehead and Morest, 1985b), and myelin matures even later (Fermin and Cohen, 1984b), but it is not at all obvious how these changes could have a selective effect on threshold.

Although there is obviously a strong parallel in these and previous data on avian hair cells and their innervation to the organization of inner and outer hair cells of the mammalian organ of Corti (Manley et al., 1989), we still do not know the role of the SHC population in the avian basilar papilla. It remains to be seen whether the organization of avian hair-cell populations is due to the same kind of division of labour as currently hypothesized for mammalian inner and outer hair cells (Patuzzi and Robertson, 1988). Recent data on the innervation patterns of tall and short hair cells is certainly compatible with such a hypothesis. Not only does a very large proportion of afferent fibres innervate THC, but the majority of SHC in the highfrequency area of the papilla receive no afferent fibres (Fischer et al., in preparation; Manley et al., 1989; Singer et al., 1989). Thus basal SHC must have a function within the hearing organ, a function that may be similar to the reverse transduction hypothesized for mammalian OHC. If this were the case, the THC would, at least at higher frequencies, be transducing a stimulus resulting partly from the passive movement of the tectorial membrane and partly from active movements of the short hair cells. The fact that the most sensitive primary fibres in the starling innervate neural THC (that is, on the neural side of the superior cartilaginous plate: Gleich, 1989; Manley et al., 1989) implies that any influence from the SHCs must be via the tectorial membrane. However, we still know too little about the mechanisms of hair-cell stimulation in birds or, indeed, in mammals.

\section{Tonotopic organization}

Recently, the use of single-fibre staining techniques has permitted tracing the origin of responses in different frequency ranges to specific locations in the papilla of the starling and the chicken (Gleich, 1989; Manley et al., 1987, 1989). A strong tonotopic organization was evident, the low frequencies being analyzed at the apical end and the high frequencies at the basal end.
The distribution of frequencies in these species is such that much less space is devoted to octaves below $1 \mathrm{kHz}$ than to those above. In the starling, the CF distribution in the low-frequency range is about $0.1 \mathrm{~mm}$ /octave, whereas at high frequencies it is (as in the chick and pigeon) near $0.6 \mathrm{~mm} /$ octave (Gummer et al., 1987; Gleich, 1989; Manley et al., 1988). In the chick, the distribution of frequencies is very similar (Manley et al., 1987; Manley, 1990). Afferent fibres leaving the avian hearing organ maintain their relative relationship to each other into the ganglion while fibre bundles from the ganglion to the brain twist together in the nerve (Boord and Rasmussen, 1963). Thus it is not unexpected to find that the various $C F$ of the nerve and cochlear ganglion are distributed highly systematically in space.

\section{Activity patterns in response to pure tones}

For excitatory stimuli, the discharge rate to a stimulus generally increases monotonically with increasing sound pressure, the mean rates over the entire stimulus sometimes exceeding 300 spikes $/ \mathrm{s}$ in animals of the older age group. These rates are often higher than equivalent rates reported for mammals (Manley, 1983). In mammalian rate-level functions, there is also a tendency for the slope of rate-level functions and the discharge rates to be lowest at frequencies above the CF (Sachs and Abbas 1974), which is at least partly traceable to the characteristics of the macromechanics of the organ of Corti (Patuzzi and Sellick, 1983). Similar rate-level functions to those presented here were reported for nerve fibres of the redwing blackbird, for which Sachs et al. (1980) describe a range of slopes and saturation characteristics resembling those found in mammals. It is interesting to note that the intensity functions at $\mathrm{CF}$ and at other frequencies differ in a parallel way in both age groups studied here. This would suggest that, if the relative slopes at and off $C F$ are determined to a significant extent by the macromechanics of the hcaring organ, as in mammals, then the basic patterns of these macromechanical motions at and off $\mathrm{CF}$ are already present in $\mathrm{P} 2$ animals.

The lower maximal discharge rates and somewhat wider mean dynamic ranges (expressed in $\mathrm{dB}$ ) in $\mathrm{P} 2$ animals at the CF, 0.32 octaves above and 0.25 octaves below CF probably indicates that at this age, the synaptic processes and/or the electrical properties of the nerve-fibre membrane are not completely developed. An examination of the durations of action potentials and their after-potentials in animals of the two age groups (a factor which could have a strong influence on maximal discharge rates) gave no indication of systematic differences in these parameters. Even though there is no significant difference in spontaneous discharge rates between the age groups, there may be differences in the size or mobilization of transmitter reserves 
needed for responses to stimuli. In addition, it is of course possible that maturation of the macromechanics also plays a significant role in steepening $\mathrm{I} / \mathrm{O}$ slopes both at $\mathrm{CF}$ and at other frequencies.

Our data thus indicate that the main change in physiological response properties of post-hatching chicks is seen in the $\mathrm{I} / \mathrm{O}$ functions of single primary fibres. With age, these functions become steeper (the dynamic range in $\mathrm{dB}$ decreases) and there is a larger difference between spontaneous rate and maximal driven rate (Fig. 7). It should be noted that the substantially higher slopes of the $\mathrm{I} / \mathrm{O}$ functions of $\mathrm{P} 21$ animals will influence the magnitude of recorded summed potentials - such as the CAP - recorded under equivalent conditions and may give the impression of a threshold shift which is not present at the level of single fibres.

\section{Single- and two-tone rate suppression}

The phenomenon of primary suppression (Gross and Anderson, 1976; Manley et al., 1985) has only been studied systematically in recent years (e.g., Hill et al., 1989a; Temchin, 1988). The use of audio-visual criteria or threshold-hunting automatic procedures to examine the tuning properties of nerve fibres has led to the tendency to ignore STRS effects, as they are not readily detected by these techniques. An automated procedure examining responses to a large matrix of frequencies and pressure levels, however, readily reveals the presence of such suppressive side-bands on tuning curves in the starling (Manley et al., 1985; Manley and Gleich, 1991). Of course, STRS effects can only be seen in cells with a significant spontaneous activity. In such response areas, the discharge rate of the cell during the stimulus falls below the spontaneous rate sometimes even to zero. Although in the case of very sensitive cells the possibility cannot be completely excluded that the fibres are not truly spontaneously active but are responding to uncontrolled, low-level noise (especially at very low frcquencies), many fibres showing this phenomenon are rather insensitive.

Primary suppression is often accompanied by an 'off' response, where the discharge rate after the stimulus offset briefly rises above the spontaneous level. In the pigeon, primary suppression areas can be symmetrical about the excitatory curve, stronger on one side or the other, or even completely absent on one side (Hill et al., 1989a; Temchin, 1988). The present data are similar, in that we found STRS both on the high side and the low side of the tuning curves, but it was sometimes absent on one or both sides, especially in cells with broader tuning curves. The sensitivity of these suppressive areas varied less than the $\mathrm{CF}$ thresholds of the individual fibres and were often almost as sensitive as the excitatory tuning curve. Such suppressive areas were not, as Temchin (1988) found in the pigeon, only seen in cells which showed preferred intervals in their spontaneous activity. Curiously, Sachs et al. (1974) report that in the pigeon nerve, 'spontaneous activity was never inhibited by acoustic stimuli'. However, STRS will not be detected by threshold routines which search for a rise in the discharge rate.

We (Manley et al., 1985) suggested that the fact that birds show primary suppression and mammals do not, may be related to the absence of a firm connection between the inner hair cells of mammals and the tectorial membrane. Unlike mammalian inner hair cells, all avian hair cells are firmly connected to the tectorial membrane (see Manley, 1990 for refs.). The participation of the tectorial membrane in two-tone effects has also been suggested for reptiles (Manley, 1990). It seems likely that these two phenomena are mediated by similar mechanisms and/or structures.

In both mammals and nonmammals, the phenomenon of two-tone rate suppression (TTRS) has similar properties to those described here for primary suppression. In mammals, the threshold for suppression of a CF tone (at about $10 \mathrm{~dB}$ above threshold) by a second tone is lower for frequencies of the second tone which lie above the high-frequency flank of the tuning curve than for frequencies of the second tone which lie below the low-frequency flank (Sachs and Kiang, 1968; Manlcy, 1983). In the chicken, we observed no consistent behaviour in this regard. TTRS has been described for the pigeon by Sachs et al. (1974) and Hill et al. (1989b). Its characteristics differ in birds from those in mammals. Thus, avian auditory-nerve fibres tend to have no particular asymmetry of the lowand high-frequency suppression areas; they may be of different size and strength and one or both may be absent.

\section{Spontaneous activity}

The distribution of spontaneous rates in birds is consistently unimodal, whereas it is bimodal in mammals (Sachs et al., 1980; Manley et al., 1985). The spontaneous rates reported here (somewhat over 20 spikes/s) are the lowest ever reported for birds. In some other avian species, the mean spontaneous activity rates of primary fibres lie above those typically recorded for mammalian auditory fibres. In the starling the mean rate of all fibres was 48 spikes/s (Manley et al., 1985), more than double that reported here for the chicken.

There is some confusion in the avian literature concerning the spontaneous rate of pigeon auditory afferents. Whereas Sachs et al. (1980) report a rate of 90 spikes/s for both the pigeon and the redwing blackbird and Temchin (1988) gives an average rate of 78 spikes/s for spontaneous activity in 26 pigeon units, Hill et al. (1989a) found an average rate of only 35 spikes/s. It would be unexpected if the rate difference 
between chicken and starling on the one hand and pigeon and redwing blackbird on the other hand (or even between different populations of pigeons) were so large. Temchin (1988) usually added a Tubocurarine analog to his anaesthetic regime for the pigeon. Sachs et al. (1974) found that the same anaesthetic technique as they used for the pigeon gave 'normal' results for the cat, making it unlikely that the difference in the bird rate data are due to anaesthetic effects. However, there are indications that differences in spontaneous rates may indeed be partly an artefact of different anaesthetic regimes or even depth of anaesthesia. In a study of primary afferents of the vestibular system in anaesthetized and unanaesthetized pigeons, for example, Anastasio et al. (1985) found the rates of spontaneous activity to be about $80 \%$ higher in the unanaesthetized state. Different anaesthetics and changing levels of anaesthesia may thus produce different degrees of depression of the activity.

\section{Preferred intervals in spontaneous activity}

The typical quasi-Poisson distribution of intervals in spontaneous data is, in avian and some reptilian afferents, strongly modified by the presence of preferred intervals. In such cells, the activity is highly non-random, such that certain intervals occur more often and others less often than expected (Gummer, 1989; Manley, 1979; Manley and Gleich, 1984; Manley et al., 1985; Temchin, 1980, 1988). A number of interesting properties of these preferred intervals have been demonstrated:

1. They are only found in some cells of relatively low $\mathrm{CF}$, mostly below $1.0 \mathrm{kHz}$. The limit in frequency would be influenced by the phase-locking ability of hair cells and nerve fibres (Gleich and Narins, 1988; Hill et al., $1989 \mathrm{c}$ ).

2. These intervals are not the result of inadvertent stimulation of the cells or of background noise (Manley et al., 1985; Temchin, 1988).

3. Within each histogram, the positions of the peaks are highly consistent (Manley et al., 1985). The interpeak intervals are inversely related to the $\mathrm{CF}$ of the cell. In the chicken data reported here and in the starling, they are on average longer than the CF period (18 and 19\%, respectively; Fig. 12 and Manley et al., 1985). In the pigeon, they are either at the CF-period (1.02 \pm 0.08 , Temchin, 1988) or are about $10 \%$ longer (Gummer, 1989).

4. Even in low-CF cells of the starling and the chicken that show no preferred intervals, the mode of the histogram is itself slightly longer the CF period (Fig. 4c) and is thus a special case of a preferred interval.

These details suggest that the spontaneous activity of many avian auditory fibres is influenced by a rhythmic behaviour of individual hair cells. Such preferred intervals have also been reported for auditory-nerve fibres of some reptiles (Manley, 1979; Crawford and Fettiplace, 1980; Eatock et al., 1981) and were interpreted as evidence for electrical tuning of hair cells. In the phase response characteristics of primary auditory fibres of the starling, Gleich (1987a,b) found evidence of an electrical tuning whose best frequency averaged 20\% lower than the acoustic CF of the cell. This corresponds well to the discrepancy noted above between preferred intervals and the period of the CF in the chicken and starling. It thus appears that in the starling and chicken, the electrical tuning mechanism has a centre frequency about $20 \%$ below that of the putative, additional, mechanical tuning frequency.

\section{The question of functional changes during development}

The tonotopic organization of the THC-afferent system of the chicken appears to be stable after hatching (Manley et al., 1987). The data of the present report indicate that essentially only those parameters of the activity of single auditory-nerve fibres of chickens that describe the discharge rates and not frequency tuning show significant changes between animals of the ages $\mathrm{P} 2$ and $\mathrm{P} 21$.

The present data indicate a small improvement in nerve-fibre threshold at the highest $\mathrm{CF}$ between P2 and P21. In the past, a number of changes in threshold have been described during development of the hearing organ of the chicken. Saunders et al. (1973) showed that the brain-stem evoked-response thresholds gradually improve more than $70 \mathrm{~dB}$ from their onset near embryonic day 12 , but mainly up to about one day after hatching. Thereafter, the thresholds changed little, as did the round-window microphonic. A rapid and very large part of this improvement in sensitivity is due to the middle ear becoming filled with air between the 19th embryonic day and hatching (Saunders et al., 1973). Unfortunately, few other studies have taken middle-ear changes into account, especially the effect of the loss of fluid from the middle ear at about the time of hatching. It is well known that fluid in the middle ear can strongly affect the sensitivity of the ear and does this in a frequency-specific fashion, acting as a low-pass filter. Some possible effects of middle-ear changes on the patterns of acoustic trauma on the papilla of the post-hatching chicken (Rubel and Ryals, 1982, 1983; Rubel et al., 1984; Ryals and Rubel, 1982, 1985a,b; Ryals et al., 1984) have been discussed elsewhere (Cotanche et al., 1984, 1987; Manley, 1990; Manley et al., 1987).

In contrast to the situation in post-hatching chickens, the kitten shows a maturational gradient both for spontaneous discharge rate and frequency selectivity (Romand, 1984). In kittens, the tuning curves change from broadly insensitive to a narrow V-shaped curve during the first 30 days after birth (Romand, 1987), a 
result which is impossible to explain by putative changes in middle-ear function. In the cat it appears as if the tuning-curve 'tip' gets added to the broad, insensitive region at a later stage of development. In gerbils, cochlear-microphonic data indicated that, although the tuning of the second turn of the cochlea does not change after the onset of hearing responses, the tuning of the basal turn does (Arjmand et al., 1988). A recent study of cochlear-ganglion cells in gerbils (Echteler et al., 1989) confirmed Romand's suggestion, that the 'tip' region of the tuning curves develops later than the low-frequency 'tail'. In contrast to this, the present report shows that tuning curves of primary fibres of chickens show the same dependence on $\mathrm{CF}$ in the age groups $\mathrm{P} 2$ and $\mathrm{P} 21$, so that any changes in tuning-curve properties must occur before hatching. Similarly, masked CAP tuning curves for chicks of different ages (Rebillard and Rubel, 1981) show almost no change in tuning sharpness with age.

Our data indicate that after hatching, the tuning properties of the chicken's inner ear change insignificantly. Thus in the post-hatching chick, not only the tonotopic organization of the hair cells on the basilar papilla, but also the tuning properties of the periphery are stable. This is remarkable, because the sensory epithelium continues to grow after hatching (Ryals et al., 1984; Manley et al., 1987). The changes we have demonstrated in the driven discharge rate properties (as seen in the $1 / O$ functions) may well be related to factors that are known to complete their maturation after hatching. For example, efferent fibres are adultlike only 1 week after hatching (Whitehead and Morest, 1985b), and myelin matures even later (Fermin and Cohen, 1984b).

\section{Acknowledgements}

Supported by a grant to GAM from the Deutsche Forschungsgemeinschaft within the SFB 204 'Gehör'.

\section{References}

Anastasio. T.J.. Correia. M.J. and Perachio, A.A. (1985) Spontaneous and driven responses of semicircular canal primary afferents in the unanaesthetized pigeon. J. Neurophysiol. 54, 335-344.

Arjmand, E. Harris, D. and Dallos, P. (1988) Developmental changes in frequency mapping of the gerbil cochlea: comparison of two cochlear locations. Hear. Res. 32, 93-96.

Boord, R.L. and Rasmussen, G.L. (1963) Projection of the cochlear and lagenar nerves on the cochlear nuclei of the pigeon. 3. Comp. Nemol. 120, 463-471.

Chandler, J.P. (1984) Light and electron microscopic studies of the basilar papilla in the duck Anas platyrhynchos. I. The hatchling. J. Comp. Neurol. 222, 506-522.

Cohen, G.M. and Fermin, C.D. (1985) Development of the embryonic chicken's tectorial membrane. Hear. Res. 18, 29-39.
Cotanche, D.A. and Sulik, K.K. (1984) The development of stereociliary bundles in the cochlear duct of chicken embryos. Develop. Brain Res. 16, 181-193.

Colanche, D.A., Tilney, L.G. and Saunders, J.C. (1984) Changes in tonotopic organization with age are due to an intensity-dependent, two-step process of hair-cell damage. Soc. Neurosci. Abstr. 10, p. 529

Cotanche, D.A. Saunders, J.C. and Tilney, L.G. (1987) Hair cell damage produced by acoustic trauma in the chicken cochlea. Hear. Res. 25, 267-286.

Cousillas, H. and Rebillard, G. (1985) Age-dependent effects of a pure-tone trauma in the chicken basilar papilla; evidence for at development of the tonotopic organization. Hear. Res. 19, $217-$ 226.

Crawford, A.C. and Fettiplace, R. (1980) The frequency selectivity of auditory nerve fibres and hair cells in the cochlea of the turtle. $J$. Physiol. 306, 79-125.

Crawford. A.C. and Fettiplace, R. (1985) The mechanical properties of ciliary bundles of turtle cochlear hair cells. J. Physiol. 364 , $359-379$

Eatock, R.A., Manley, G.A. and Pawson, L. (1981) Auditory nerve fibre activity in the tokay gecko: I, implications for cochlear processing. J. Comp. Physiol. A 142, 203-218.

Echteler, S.M., Arjmand. E. and Dallos, P. (1989) Developmental alteration in the frequency map of the mammalian cochlea. Science 341. 147-149.

Fermin. C.D. and Cohen, G.M. (1984a) Developmental gradients in the embryonic chicken's basilar papilla. Acta Otolaryngol. 97. $39-51$.

Fermin. C.D. and Cohen. G.M. (1984b) Development of the embryonic chick's statoacoustic ganglion. Acta Otolaryngol. 98, 42-52.

(ileich. O. (1987a) Fvidence for electrical tuning in the starling inner ear. In: N. Elsner and O. Creutzfeldt (Eds.). New Frontiers in Brain Research. Thieme Verlag, Stuttgart, New York. p. 101.

Gleich, O. (1987b) Electrical tuning in the avian inner ear. Abstr. Assoc. Res. Otolaryngol. p.22.

Gleich. O. (1989) Auditory primary afferents in the starling: Correlation of function and morphology. Hear. Res. 37, 255-267.

Gleich, O. and Narins, P.M. (1988) The phase response of primary auditory afferents in a songbird (Sturmus culgaris L.). Hear. Res. 32. $81-91$.

Gray, L. and Rubel, E.W. (1985) Development of absolute thresholds in chickens. J. Acoust. Soc. Am. 77, 1162-1172.

Gross, N.B. and Anderson, D.J. (1976) Single unit responses recorded from the first order neuron of the pigeon auditory system. Brain Res. 101. 209 222

Gummer, A.W. (1989) Spontaneous activity in the cochlear ganglion of the pigcon. Abstr. 26th Workshop Inner Ear Biology. P25.

Gummer, A.W., Smolders, J.W.T. and Klinke, R. (1987) Basilarmembrane motion in the pigeon measured with the Mossbauer technique. Hear. Res. 29, 63-92.

Haeseler, C., Brix, J. and Manley, G.A. (1989) Innervation patterns and spontaneous activity of afferent fibres to the chicken's lagenar macula. In: N. Elsner and W. Singer (Eds.), Dynamics and Plasticity in Neural Systems. Thieme-Verlag, Stuttgart, F.R.G. p. 282 .

Hill, K.G., Mo, J. and Stange, G. (1989a) Excitation and suppression of primary auditory fibres in the pigeon. Hear. Res. 39. 37-48.

Hill, K.G., Mo, J. and Stange, G. (1989b) Induced suppression in spike responses to tone-on-noise stimuli in the auditory nerve of the pigenn. Hear Res. 39,49-62

Hill, K.G., Stange, G. and Mo, J. (1989c) Temporal synchronization in the primary auditory response in the pigeon. Hear. Res. 39. 6.3-74.

Hirokawa, N. (1978) The ultrastructure of the basilar papilla of the chicken. J. Comp. Neurol. 181, 361-374. 
Lippe, W.R. (1987) Shift of tonotopic organization in brain stem auditory nuclei of the chicken during late embryonic development. Hear. Res. 25, 205-208

Lippe, W.R. and Rubel, E.W. (1985) Ontogeny of tonotopic organization of brain stem auditory nuclei in the chicken: implications for development of the place principle. J. Comp. Neurol. 237, 273-289.

Manley, G.A. (1979) Preferred intervals in the spontaneous activity of primary auditory neurones. Naturwissenschaften 66,582 .

Manley, G.A. (1983) Auditory nerve fibre activity in mammals. In: B. I ewis (Ed.), Rioacoustics, Academic Press, I ondon, New York, pp. 207-232.

Manley, G.A. (1990) Peripheral hearing mechanisms in reptiles and birds, Springer-Verlag, Berlin, Heidelberg, New York

Manley, G.A. and Leppelsack, H-J. (1977) Preliminary data on activity patterns of cochlear ganglion neurones in the starling. In: M. Portmann and J.-M. Aaron (Eds.), Inner ear biology XIVth workshop, INSERM, Paris, pp. 127-136.

Manley, G.A. and Gleich, O. (1984) Avian primary auditory neurones: the relationship between characteristic frequency and preferred intervals. Naturwissenschaften 71, 592-594.

Manley, G.A. and Gleich, O. (1991) Evolution and specialization of function in the avian auditory periphery. In: R.R. Fay, A.N. Popper and D.B. Webster (Eds.), The evolutionary biology of hearing, Springer-Verlag, Heidelberg, New York. (in press).

Manley, G.A., Gleich, O., Leppelsack, H.-J. and Oeckinghaus, H. (1985) Activity patterns of cochlear ganglion neurones in the starling. J. Comp. Physiol. A 157, 161-181.

Manley, G.A., Brix, J. and Kaiser, A. (1987) Developmental stability of the tonotopic organization of the chicken's basilar papilla. Science 237, 655-656.

Manley, G.A., Brix, J., Gleich, O., Kaiser, A., Köppl, C. and Yates, G.K. (1988) New aspects of comparative peripheral auditory physiology. In: J. Syka and R.B. Masterton (Eds.), Auditory Pathway - Structure and Function. Plenum Press, London, N.Y. pp. 3-12.

Manley, G.A., Haeseler, C. and Brix, J. (1991) Innervation patterns and spontaneous activity of afferent fibres to the lagenar macula and apical basilar of the chick's cochlea. Hear. Res. 56, 211-226.

Manley, G.A., Gleich, O., Kaiser, A. and Brix, J. (1989) Functional differentiation of sensory cells in the avian auditory periphery. $\mathbf{J}$. Comp. Physiol. A 164, 289-296.

Patuzzi, R. and Sellick, P.M. (1983) A comparison between basilar membrane and inner hair cell receptor potential input-output functions in the guinea pig cochlea. J. Acoust. Soc. Am. 74, 1734-1741.

Patuzzi, R. and Robertson, D. (1988) Tuning in the mammalian cochlea. Physiol. Rev. 68, 1009-1082.

Rebillard, M. and Pujol, R. (1983) Innervation of the chicken basilar papilla during its development. Acta Otolaryngol. 96, 379-388.

Rebillard, G. and Rubel, E.W. (1981) Electrophysiological study of the maturation of auditory responses from the inner ear of the chicken. Brain Res. 229, 15-23.

Rebillard, G., Ryals, B.M. and Rubel, E.W. (1982) Relationship between hair cell loss on the chick basilar papilla and threshold shift after acoustic overstimulation. Hear. Res. 8, 77-81.

Romand, R. (1984) Functional properties of auditory-nerve fibres during post-natal development in the kitten. Exp. Brain Res. 56, 395-402.

Romand, R. (1987) Tonotopic evolution during development. Hear. Rcs. 28, 117-123.
Rubel, E.W. and Ryals, B.M. (1982) Patterns of hair-cell loss in chicken basilar papilla after intense auditory stimulation: exposure duration and survival time. Acta Otolaryngol. 93, 31-41.

Rubel, E.W. and Ryals, B.M. (1983) Development of the place principle: acoustic trauma. Science 219, 512-514.

Rubel, E.W., Lippe, W.R. and Ryals, B.M. (1984) Development of the place principle. Ann. Otol. Rhinol. Laryngol. 6, 609-615.

Ryals, B.M. and Rubel, E.W. (1982) Patterns of hair-cell loss in chicken basilar papilla after intense auditory stimulation. Acta Otolaryngol. 93, 205-210.

Ryals, B.M. and Rubel, E.W. (1985a) Differential susceptibility of avian hair cells to acoustic trauma. Hear. Res. 19, 73-84.

Ryals, B.M. and Rubel, E.W. (1985b) Ontogenetic changes in the position of hair cell loss after acoustic overstimulation in the avian basilar papilla. Hear. Res. 19, 135-142.

Ryals, B.M., Creech, H.B. and Rubel, E.W. (1984) Postnatal changes in the size of the cochlear duct. Acta Otolaryngol. 98, 93-97.

Sachs, M.B, and Abbas, P.J. (1974) Rate versus level functions for auditory-nerve fibres in cats: tone-burst stimuli. J. Acoust. Soc. Am. 56, 1835-1847.

Sachs, M.B. and Kiang, N.Y-S. (1968) Two-tone inhibition in auditory-nerve fibres. J. Acoust. Soc. Am. 43, 1120-1128.

Sachs, M.B., Lewis, R.H. and Young, E.D. (1974) Discharge patterns of single fibers in the pigeon auditory nerve. Brain Res. 70, $431-447$.

Sachs, M.B., Woolf, N.K. and Sinnott, J.M. (1980) Response properties of neurons in the avian auditory system: comparisons with mammalian homologues and consideration of the neural encoding of complex stimuli. In: A.N. Popper and R.R. Fay (Eds.), Comparative studies of hearing in vertebrates, Springer-Verlag, New York, Heidelberg, Berlin, pp. 323-353.

Saunders, J.C., Coles, R.G. and Gates, G.R. (1973) The development of auditory evoked responses in the cochlea and cochlear nuclei of the chicken. Brain Res. 63, 59-74.

Saunders, J.C., Relkin, E.M., Rosowski, J.J. and Bahl, C. (1986) Changes in middle-ear input admittance during postnatal development in chickens. Hear. Res. 24, 227-235.

Schermuly, L. and Klinke, R. (1990) Infrasound sensitive neurones in the pigeon cochlear ganglion. J. Comp. Physiol. A 166, 355-363.

Schwartzkopff, J.J. and Bremond, J. (1963) Méthode de dérivation des Potentials cochléailes chex l'oiseau. J. Physiol. (Paris) 55, 495-518.

Singer, I., Fischer, F.P. and Manley, G.A. (1989) Hair-cell innervation in the basilar papilla of the European starling (Sturnus vulgaris). Abstr. 26th Inner-ear Biology Meet. Paris. P 60.

Temchin, A.N. (1980) Multimodality of the interspike distribution of spontaneous activity in pigeon's auditory nerve fibres (in Russian). Dokl. Akad. Nauk. S.S.S.R. 253, 773-747.

Temchin, A.N. (1988) Discharge patterns of single fibres in the pigeon's auditory nerve. J. Comp. Physiol. A 163, 99-115.

Tilney, L.G., Tilney, M.S., Saunders, J.C. and DeRosier, D.J. (1986) Actin filaments, stereocilia, and hair cells of the bird cochlea. III. The development and differentiation of hair cells and stereocilia. Develop. Biology 116, 100-118.

Whitehead, M.C. and Morest, D.K. (1985a) The development of innervation patterns in the avian cochlea. Neuroscience 14,255 276.

Whitehead, M.C. and Morest, D.K. (1985b) The growth of cochlear fibres and the formation of their synaptic endings in the avian inner ear: A study with the electron microscope. Neuroscience $14,277-300$. 